\title{
Desenvolvimento de biscoitos salgados com o uso de subprodutos da indústria de cerveja
}

\author{
Helena Dupke Glüger ${ }^{1}$ e Poliana Deyse Gurak²
}

Este estudo avaliou a potencialidade tecnológica da incorporação de farinha de bagaço de malte em biscoitos salgados do tipo aperitivo. Primeiramente produziu-se a farinha de bagaço de malte (FBM), em seguida testes de desenvolvimento de biscoito foram realizados com aplicações de 0\% (FP), 25\% (F25) e 50\% (F50) de FBM em substituição à farinha de trigo. Resultados mostraram que a FBM produzida apresentou $16 \%$ de proteínas e índices de absorção de água e óleo e solubilidade em água maiores quando comparados à farinha de trigo. A incorporação da FBM nas formulações de biscoitos promoveu aumento no teor de cinzas, proteínas e lipídeos, também diminuiu o teor de umidade, carboidratos e ocasionou alterações sensoriais conforme o percentual aplicado da FBM. Biscoitos com 25\% de FBM tiveram maior aceitabilidade ( $>70 \%$ ) quando comparada aos biscoitos com 50\% de FBM $(<70 \%)$. Por fim, o subproduto da indústria cervejeira mostrou ser um insumo possível para o desenvolvimento de novos produtos destinados à alimentação humana, além de incentivar os cuidados com o meio ambiente.

Palavras-chave: Subproduto da indústria cervejeira; composição físico-química; análise sensorial.

\section{Salty crackers development with the use of by-products from the beer industry}

This study evaluated the technological potential of incorporating malt bagasse flour into snack crackers. Firstly, malt bagasse flour (FBM) was produced, then biscuit development tests were carried out with applications of $0 \%$ (FP), 25\% (F25) and 50\% (F50) of FBM to replace the wheat. Results showed that the FBM produced had 16\% protein and water and oil absorption rates and water solubility higher when compared to wheat flour. The incorporation of FBM in biscuit formulations promoted an increase in the content of ash, protein and lipids, also decreased the content of moisture, carbohydrates and caused sensory changes according to the percentage applied to FBM. Biscuits with 25\% FBM had greater acceptability (> 70\%) when compared to biscuits with $50 \%$ FBM $(<70 \%)$. Finally, the by-product of the brewing industry proved to be a possible input for the development of new products for human consumption, in addition to encouraging care for the environment.

Keywords: Brewing industry by-product; physical-chemical composition; sensory analysis.

\footnotetext{
${ }^{1}$ Universidade Federal de Ciências da Saúde de Porto Alegre, Departamento de Nutrição. Endereço para Correspondência: Rua Sarmento Leite no 245. Bairro Centro Histórico, Porto Alegre, Rio Grande do Sul, Brasil. CEP: 90050-170.Tel.: (51) 3303-8830.E-mail. helenagluger@hotmail.com

${ }^{2}$ Universidade Federal de Ciências da Saúde de Porto Alegre, Departamento de Nutrição. Endereço para Correspondência: Rua Sarmento Leite no 245. Bairro Centro Histórico, Porto Alegre, Rio Grande do Sul, Brasil. CEP: 90050-170. Tel.: (51) 3303-8830. E-mail: gurak@ufcspa.edu.br. ORCID: 0000-0002-0831-1407
} 


\section{INTRODUÇÃO}

O Brasil é o terceiro maior produtor mundial de cerveja, contando com cervejarias de todos os portes e formatos, desde grandes até artesanais e itinerantes. É considerado um setor expressivo na economia brasileira com uma produção anual de mais de 14 bilhões de litros da bebida. O país fechou o ano de 2018 com 889 cervejarias registradas junto ao órgão regulamentador e crescimento de $23 \%$ quando comparado ao ano anterior $[1,2,3]$.

Ao examinar o processo produtivo cervejeiro, observa-se que o mesmo tem como característica a entrada de poucos insumos, basicamente água, malte, lúpulo e levedura, para a produção da bebida, seguindo a Lei da Pureza Alemã. Porém ocorre a geração de três diferentes resíduos sólidos, o bagaço de malte, a levedura residual e o trub, retirados em diferentes etapas durante o processamento ${ }^{[4,5]}$.

O bagaço de malte é retirado após a etapa de brassagem, onde ocorre a filtração do mosto produzido, e sendo utilizados como elementos filtrantes as próprias cascas do malte presentes no mosto. A parte sólida retida é denominada bagaço de malte ou dreche, e é o primeiro resíduo sólido gerado no processo, o qual representa cerca de $85 \%$ dos resíduos totais, sendo gerados de 14 a $20 \mathrm{~kg}$ a cada 100 litros de cerveja produzida[5,6,7,8]. Este resíduo é composto de aproximadamente $70 \%$ de fibras e $20 \%$ de proteínas em sua composição. Em relação a outros componentes, apresenta seu perfil lipídico composto majoritariamente de ácidos graxos insaturados, além de apresentar compostos bioativos como os flavonóides e o ácidos fenólicos.

Outra característica importante é que bagaço de malte apresenta cerca de $80 \%$ de umidade. Desta forma, para melhorar a conservação dos resíduos gerados e o seu potencial de aproveitamento na alimentação humana, podem ser utilizados os processos de desidratação para redução da atividade de água, volume e possível carga microbiana presente[ ${ }^{[6,9,10]}$.

Inúmeros estudos enfatizam aspectos de sustentabilidade e de saúde ao aproveitar este resíduo na alimentação humana. Entretanto, para ocorrer seu uso como um insumo alimentar, é recomendado alguns processos tecnológicos que garantam a segurança de alimentos pela redução, principalmente da atividade de água[9,11].

Pensando no segmento de panificação, é sabido que biscoitos em suas diversas classificações e apresentações, estão presentes em 99,6\% dos lares brasileiros, inclusive integrando a cesta básica do país, apresentando um consumo médio de $5,500 \mathrm{~kg}$ por habitante por ano. Em 2018, a produção nacional de biscoitos foi de 1.157.051 toneladas, sendo destas 253.460 toneladas de biscoitos água e sal/cream cracker e 83.700 toneladas de biscoito salgado[12]. Assim, a aplicação do bagaço de malte na produção de "aperitivos", como biscoitos salgados saborizados seguem algumas tendências atual de mercado, entre elas: elaborar produtos mais sustentáveis e com melhor aporte de nutrientes ${ }^{[2,13]}$. Desta forma, a fim de realizar o aproveitamento do resíduo, mais expressivo, gerado na indústria cervejeira; o presente trabalho desenvolveu e avaliou a qualidade físicoquímica e sensorial de "biscoito salgado", com substituição parcial da farinha de trigo por farinha de bagaço de malte, sendo a farinha também desenvolvida para o alcance dos objetivos.

\section{MATERIAIS E MÉTODOS}

\section{Materiais}

O bagaço de malte úmido, proveniente da produção de cerveja do tipo pilsen, foi gentilmente cedido por uma cervejaria localizada na cidade de Dois Irmãos, Rio Grande do Sul, Brasil e seguiu todas as boas práticas de fabricação instituídas pela cervejaria parceira. O resíduo era composto, basicamente, por cascas do grão de malte e foi transportado em recipiente adequado e devidamente higienizado, sendo entregue no mesmo dia de retirada aos pesquisadores e em seguida processado de acordo com as etapas do presente estudo. Os demais ingredientes foram adquiridos no comércio local e todos os reagentes utilizados apresentavam grau analítico.

\section{Produção da farinha de bagaço de malte}

Para produção da farinha, o bagaço de malte úmido foi disposto em assadeiras, sendo estas levadas ao forno combinado (Wictory 110 LTedesco modelo WC5E) modo seco com circulação de ar forçado à $78^{\circ} \mathrm{C}$ por 12 horas. A condição de secagem foi 
definida após pesquisa bibliográfica e testes preliminares ${ }^{[9,14]}$. Após secagem o bagaço de malte foi triturado em mixer (Vorwerk) e peneirado em agitador magnético de peneiras redondas para análises granulométricas (Bertel Insdústria Metalúrgica LTDA) com peneira para análise granulométrica (do mesmo fornecedor) com abertura de $425 \mathrm{~mm}$ (ABNT/ASTM 40; TYLER/MESH 35). O produto retirado ao final do agitador foi pesado e disposto em sacos de polietileno (rip lock) selados e acondicionados em freezer até dia do uso. A partir dos pesos obtidos, inicial e final, foi possível calcular o rendimento de produção. O produto final recebeu o código FBM (farinha de bagaço de malte).

\section{Elaboração dos biscoitos salgados acrescidos de farinha de bagaço de malte}

Foram desenvolvidas três formulações diferentes de biscoitos, sendo os ingredientes invariáveis a água (40\%), a gordura de palma (20\%), o sal $(1,5 \%)$ e a mistura de temperos $(3 \%)$. A farinha de trigo e a farinha de bagaço de malte variaram em diferentes proporções de acordo com as formulações previamente estabelecidas: 0, 25 e 50\% de FBM em relação à farinha de trigo (quantidade suficiente para 100\%). A mistura de temperos foi preparada utilizando-se partes iguais de orégano, alecrim, manjerona, sálvia e tomilho.

O preparo dos biscoitos iniciou-se com a pesagem dos ingredientes, sendo estes posteriormente misturados manualmente em recipiente apropriado. Em seguida a massa obtida para cada uma das três formulações foi laminada em cilindro até espessura de $1 \mathrm{~mm}$ e cortada com ajuda de um molde em pequenos quadrados de $5 \mathrm{~cm}$ de comprimento e largura, os quadrados foram dispostos sobre assadeiras e levados ao forno combinado (Wictory 110 LTedesco modelo WC5E) modo seco à $180^{\circ} \mathrm{C}$ por 10 minutos. Ao fim do processo, com os biscoitos já frios, os mesmos foram acondicionados em sacos de polietileno (zip lock) até o momento da análise. Cada formulação foi codificada da seguinte maneira: formulação padrão sem adição de farinha de bagaço de malte (FP), formulação com $25 \%$ de farinha de bagaço de malte em substituição a farinha de trigo (F25) e formulação com $50 \%$ de farinha de bagaço de malte em substituição a farinha de trigo (F50).

\section{Descrição das metodologias}

\section{Análises fisico-químicas da farinha de bagaço de malte e dos biscoitos}

Em relação à composição centesimal realizouse análises de umidade (Método Oficial 012/IV)[15], cinzas (Método Oficial 018/IV) ${ }^{15]}$, proteínas (Método Oficial 037/IV) [15], com fator de conversão de 6,25, lipídeos (Método Oficial 032/IV) ${ }^{[15]}$ e carboidratos (método da diferença com os valores encontrados para umidade, cinzas, proteínas e lipídeos [15,16]. Foram realizadas também análises de $\mathrm{pH}$ (Método Oficial 017/IV [15] e acidez (Método Oficial 016/IV] ${ }^{[15]}$, índice de absorção de água, índice de absorção de óleo e índice de solubilidade em água, foram realizadas apenas para a amostra de farinha de bagaço de malte[17]. A cor foi medida por um espectrocolorímetro Color Quest XE (marca Hunter Lab, EUA) equipado com iluminante D65 e ângulo de observação de $10^{\circ}$, leitura de modo reflectância especular excluída por leitura direta[18]. Através do software do equipamento, foram determinados os seguintes parâmetros: $L^{*}$, $a^{*}$ e $b^{*}$. No sistema CIELAB L representa a luminosidade $\left(L^{*}=0\right.$ é preto e $L^{*}=100$ claridade total). As coordenadas que indicam a direção das cores são: $+a^{*}=$ vermelho e $a^{*}=$ verde; $+b^{*}=$ amarelo e $-b^{*}=$ azul. Além destas coordenadas de cores, também foi feita a leitura dos parâmetros de cor como o valor de croma $C^{*}$ ab, que representa a pureza da cor, e a medida do ângulo $h_{a b}$, que representa a tonalidade da cor. Para análise de atividade de água, utilizou-se analisador de atividade de água (LabMaster-aw, modelo CH-8863) à temperatura de $25^{\circ} \mathrm{C}[18]$. Todas as determinações do presente estudo foram realizadas em triplicata.

\section{Tabelas nutricionais teóricas dos biscoitos}

As tabelas nutricionais teóricas das formulações de biscoito foram desenvolvidas seguindo como referência as informações da USDA (United States Department of Agriculture) - Food Composition Data bases (Departamento de Agricultura dos Estados Unidos - Bancos de dados de Composição de Alimentos) ${ }^{[19]}$. Como porção de referência e medida caseira utilizou-se o valor de $30 \mathrm{~g}$ igual a 3 unidades, tendo como base a RDC № 359/2003[20]. Para conhecimento, a composição da mistura de temperos foi desconsiderada para fins de cálculos. 


\section{Análise sensorial dos biscoitos}

A análise sensorial dos biscoitos elaborados foi autorizada pelo comitê de ética da Univerisdade Federal de Ciências da Saúde de Porto Alegre (UFCSPA) encontrando-se inscrita sob o número 12823819.0.0000.5345. A análise foi realizada seguindo metodologia descrita pelo Instituto Adolfo Lutz (2008)[15], por meio de teste sensorial afetivo de aceitação, preferência e intenção de compra, realizado com 127 participantes voluntários. Os julgadores atenderam aos seguintes pré-requisitos: pessoas de todos os gêneros maiores de 18 anos, saudáveis e que não possuíssem alergia ao glúten ou outros tipos de alergias e/ou intolerâncias com algum dos ingredientes dos biscoitos desenvolvidos (malte, gordura de palma, sal e temperos - orégano, alecrim, manjerona, sálvia e tomilho).

Os julgadores foram convidados para a realização do presente projeto por meio de convite de divulgação e Termo de Consentimento Livre e Esclarecido (TCLE). Os testes foram realizados em cabines individuais com iluminação artificial adequada na cor branca. Todos os julgadores aprovados receberam um prato descartável de cor branca com uma unidade amostral de cada formulação, de forma padronizada e em temperatura ambiente, codificadas com números de 3 dígitos aleatórios $(\mathrm{FP}=582 ; \mathrm{F} 25=$ 159; $\mathrm{F} 50=371)$, acompanhado de guardanapo descartável e copo descartável com água, para limpeza do palato entre uma amostra e outra. Foi fornecida também a ficha de avaliação para teste de aceitação dos atributos cor, sabor, aroma e textura (crocância) utilizando-se escala hedônica de 9 pontos, entre desgostei muitíssimo e gostei muitíssimo. E foi solicitado que o julgador indicasse a preferência entre as amostras além da intenção de compra para cada uma.

As respostas obtidas por meio do teste sensorial foram computadas em planilha Excel e analisadas. A partir dos dados obtidos para os atributos de aceitação de cor, sabor, aroma e textura foi calculado o índice de aceitabilidade. O critério de decisão utilizado para o índice ser de boa aceitação foi igual ou superior a $70 \%{ }^{[21]}$.

\section{Testes estatísticos}

Os resultados obtidos no presente estudo foram expressos em média \pm desvio padrão. Para avaliação dos resultados obtidos foram realizados diferentes testes estatísticos dependendo da avaliação necessária para cada conjunto de dados, sendo eles o Teste $t$, ANOVA, Teste de Tukey e Teste QuiQuadrado. Considerou-se $5 \%$ de probabilidade $(p$ valor $<0,05)$, e todos os testes foram elaborados por meio do programa IBM-SPSS Statistics 23.

\section{RESULTADOS E DISCUSSÃO}

\section{Obtenção e análises da farinha de bagaço de malte}

Os estágios de processamento do bagaço de malte até a obtenção da farinha final podem ser observados na Figura 1. Ao final do processamento do bagaço de malte úmido obteve-se a farinha de bagaço de malte com rendimento de $17,92 \%$. Este percentual de rendimento pode ser explicado pelo percentual de umidade do subproduto, que pode variar entre $77 \mathrm{e}$ $81 \%[0,13]$.

Figura 1. Processamento do bagaço de malte

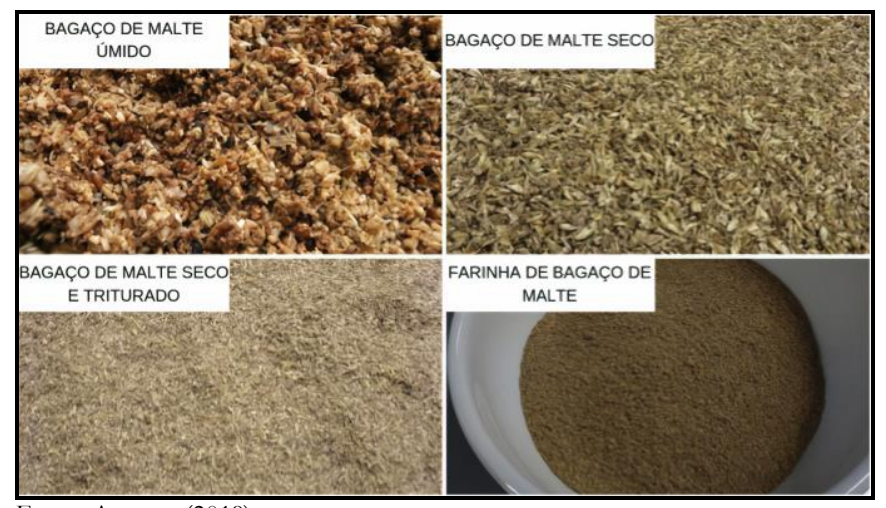

Fonte: Autores (2019).

Os resultados obtidos nas análises realizadas para caracterização da farinha de bagaço de malte (FBM) podem ser visualizados na Tabela 1. A FBM apresentou umidade de 4,19\%. A composição físicoquímica e propriedades tecnológicas da FBM para a farinha de trigo são diferentes, o que ressalta a importância de caracterização da FBM. Para conhecimento, o regulamento técnico de identidade e qualidade da farinha de trigo estabelecido pela Instrução Normativa no 8, de 3 de junho de 2005 do MAPA estabelece umidade máxima de $15 \%$ a farinha 
de trigo ${ }^{[22]}$ e este valor não deve seguir de parâmetro para a FBM. Estudos que analisaram farinhas de bagaço de malte encontraram valores de 5,20 à 6,32\% de umidade[9, 10,23], ou seja próximos a este trabalho. $\mathrm{O}$ percentual de cinzas detectado também permaneceu de acordo com os valores de 3,04 a 3,82\% encontrados nos trabalhos referenciados ${ }^{[9,10,23]}$. Assim como para proteínas, que apresentou valor de 16,61\% encontrando-se dentro da faixa de valores expostos pelos outros estudos supracitados (12,50 à $20,30 \%)^{[9,10,23]}$. Os lipídeos na FBM foi de 4,79\%, enquanto outros trabalhos variam de 5,90 à $8,32 \%$. Por fim o valor de carboidratos obtido por diferença no presente estudo foi de $71,37 \%$, o qual se aproxima do valor encontrado por RIGO et al. de 73\%[23].

Tabela 1. Caracterização físico-química da farinha de bagaço de malte (FBM)

\begin{tabular}{lc}
\hline Amostra & FBM \\
Umidade (\%) & $4,19 \pm 0,03$ \\
Cinzas (\%) & $3,04 \pm 0,03$ \\
Proteínas (\%) & $16,61 \pm 0,10$ \\
Lipídeos (\%) & $4,79 \pm 0,06$ \\
Carboidratos (\%) & $71,37 \pm 0,08$ \\
$\mathrm{pH}$ & $4,64 \pm 0,05$ \\
Acidez (\%) & $2,18 \pm 0,02$ \\
Atividade de água & $0,46 \pm 0,00$ \\
$L^{*}$ (luminosidade) & $67,03 \pm 0,41$ \\
$a^{*}$ (verde à vermelho) & $5,14 \pm 0,03$ \\
$b^{*}$ (amarelo à azul) & $15,35 \pm 0,15$ \\
$C^{*}$ ab (saturação) & $16,19 \pm 0,13$ \\
$\mathrm{~h}_{\mathrm{ab}}$ (tonalidade) & $1,25 \pm 0,00$ \\
Índice de Absorção de Água & $4,16 \pm 0,03$ \\
(g/g) & $16,75 \pm 0,07$ \\
Índice de Solubilidade em Água & $3,54 \pm 0,01$ \\
(g/g) &
\end{tabular}

Fonte: Autores (2019).

As diferenças observadas entre os valores encontrados em distintos estudos para a composição centesimal da farinha de bagaço de malte são compreensíveis, uma vez que diversos fatores podem vir a influenciar a composição final da farinha. Como por exemplo a variação dos maltes utilizados para cada estilo de cerveja produzida, o tempo de colheita da cevada e também a qualidade e os tipos de adjuntos utilizados no processo de fabricação da cerveja. Estes fatores também podem influenciar o $\mathrm{pH}$ e a acidez final da farinha de bagaço de malte produzida, assim como o tratamento térmico empregado para a produção[13].

No presente estudo o $\mathrm{pH}$ da FBM foi de 4,63, enquanto para Almeida ${ }^{[10]}$, em seu estudo detectou valor de 5,93, demostrando que farinhas produzidas a partir de bagaço de malte possuem $\mathrm{pH}$ ácido. A acidez também foi analisada e apresentou valor de 2,17\% de $\mathrm{HCl}$. No estudo de Almeida um valor de $8,03 \%$ de $\mathrm{HCl}$ foi identificado ${ }^{[10]}$. A diferença entre esses valores de acidez ocorre devido condições de processamento e da matéria-prima diferentes. Uma temperatura mais elevada durante a secagem do resíduo ocasiona a perda de ácidos, gerando uma menor acidez como a encontrada no presente estudo[24].

A atividade de água da FBM produzida foi de 0,46 , encontrando-se abaixo da faixa esperada para farinhas situada ente 0,85 e $0,60[25]$. Alimentos com atividade de água abaixo de 0,60 não são favoráveis para a multiplicação de microrganismos, sendo considerados microbiologicamente estáveis.

Como característica geral a composição do bagaço de malte apresenta altos valores de fibras e proteínas, cerca de 70 e $20 \%$ da sua composição respectivamente[?], quando comparado a farinha de trigo. Estes altos valores demostram melhor composição nutricional, valor calórico inferior e diferente comportamento das propriedades funcionais tecnológicas ao comparar com a farinha de trigo usualmente utilizada na produção de biscoitos e demais panificados.

A amostra de FBM apresentou valores significativamente ( $p$-valor $<0,001)$ maiores de absorção de água e óleo e solubilidade em água quando comparada à farinha de trigo convencional. Também pode ser observado, conforme dados da Tabela 1, que a absorção de água foi maior que a absorção de óleo para a FBM, indicando uma baixa retenção de óleo quando compara a retenção de água.

A absorção de água é atribuída, principalmente, ao teor de fibras. E o acréscimo de uma farinha com alta absorção de água em produtos de panificação permite uma maior adição de água na 
massa produzindo texturas mais macias e, consequentemente, diminuindo o ressecamento durante o armazenamento do produto[26]. Se comparados os valores encontrados no presente estudo para FBM e farinha de trigo, observa-se que o índice apresentado para FBM (4,16 g/g) é 2,22 vezes maior que o índice apresentado para farinha de trigo $(1,87 \mathrm{~g} / \mathrm{g})$, indicando que a farinha produzida a partir do bagaço de malte é rica em fibras quando comparada a farinha de trigo.

O índice de absorção de óleo está relacionado às ligações de partes protéicas da amostra às moléculas de óleo, quanto maior a absorção de óleo da amostra, maior a sua capacidade de emulsão, indicando seu uso para produtos cárneos, maionese, molhos para salada, sopas, queijos processados, massas de bolo, entre outros ${ }^{[26]}$. Esta característica, de maior absorção de óleo, melhora a palatabilidade do alimento por conferir propriedades adequadas de consistência, viscosidade e adesão, melhorando a qualidade da textura e facilitando seu uso como ingredientes análogos ou substitutos em formulações alimentares ${ }^{[27]}$. Ao comparar os valores encontrados no presente estudo para FBM e farinha de trigo, observa-se que o índice apresentado para FBM $(3,54 \mathrm{~g} / \mathrm{g})$ é 1,13 vezes maior que o apresentado para farinha de trigo $(3,13 \mathrm{~g} / \mathrm{g})$, indicando que a farinha produzida a partir do bagaço de malte possui maior capacidade de emulsão quando comparada à farinha de trigo.

O índice de solubilidade em água indica a capacidade de solubilização da amostra à baixa temperaturas sendo indicado o seu uso para alimentos instantâneos ou até mesmo como ingrediente em sopas, sobremesas, molhos, que necessitam de ingredientes com maior solubilidade em água [26]. Se comparar os valores encontrados no presente estudo para FBM e farinha de trigo, observa-se que a solubilidade da FBM $(16,75 \mathrm{~g} / \mathrm{g})$ é 2,13 vezes maior que a apresentada para farinha de trigo $(7,85 \mathrm{~g} / \mathrm{g})$, indicando que a farinha de bagaço de malte possui maior solubilidade em água á baixas temperaturas quando comparada à farinha de trigo, assim seu uso pode ser sugerido também para produtos de solubilidade instantânea.

Os resultados da análise colorimétrica também podem ser observados na Tabela 1. A amostra de FBM apresentou valor para $L^{*}$ (luminosidade) mais próximo ao campo escuro. Já em relação aos parâmetros $a^{*}$ e $b^{*}$, a amostra de FBM apresentou valores mais próximos aos campos de cor vermelho e amarelo. A partir destes parâmetros podese determinar o croma $\left(\mathrm{C}_{a b}{ }^{*}\right)$ e o ângulo hue $\left(\mathrm{h}_{\mathrm{ab}}\right)$, que indicam a intensidade e tonalidade, respectivamente. A amostra possui intensidade média e tonalidade baixa. Ou seja, a amostra encontra-se no campo de cor mais próximo ao marrom, com luminosidade escura, porém com média intensidade e uma tonalidade baixa.

\section{Caracterização dos biscoitos elaborados com farinha de bagaço de malte}

Os biscoitos elaborados para o presente estudo podem ser visualizados na Figura 2 , e os resultados das análises realizadas para cada uma das formulações de biscoito desenvolvidas estão presentes na Tabela 2.

Figura 2. Formulações de biscoitos contento farinha de bagaço de malte em diferentes concentrações: $0 \%$ (FB), 25\% (F25) e 50\% (F50)

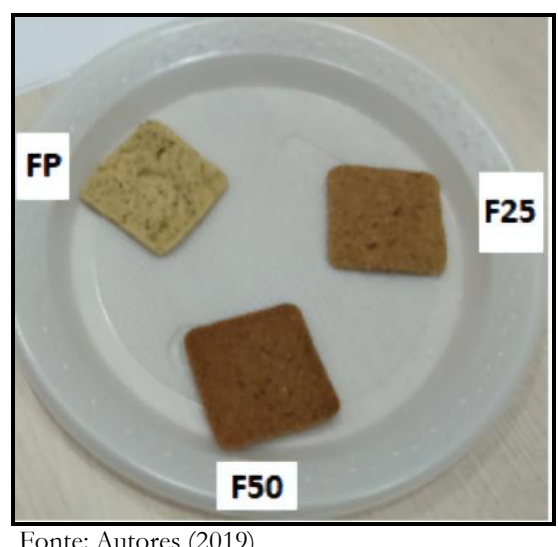


Tabela 2. Resultados análises biscoitos. FP= formulação padrão. $\mathrm{F} 25=$ formulação com $25 \%$ de farinha de bagaço de malte. $\mathrm{F} 50=$ formulação com $50 \%$ de farinha de bagaço de malte*

\begin{tabular}{lccc}
\hline \multicolumn{1}{c}{ Amostras } & FP & F25 & F50 \\
\hline Umidade (\%) & $1,78 \pm 0,00^{\mathrm{a}}$ & $1,65 \pm 0,00^{\mathrm{b}}$ & $1,18 \pm 0,00^{\mathrm{c}}$ \\
Cinzas (\%) & $2,44 \pm 0,02^{\mathrm{a}}$ & $3,65 \pm 0,04^{\mathrm{b}}$ & $4,10 \pm 0,02^{\mathrm{c}}$ \\
Proteínas (\%) & $9,82 \pm 0,00^{\mathrm{a}}$ & $10,89 \pm 0,07^{\mathrm{b}}$ & $12,62 \pm 0,14^{\mathrm{c}}$ \\
Lipídeos (\%) & $15,44 \pm 0,16^{\mathrm{a}}$ & $17,75 \pm 0,13^{\mathrm{b}}$ & $19,33 \pm 0,16^{\mathrm{c}}$ \\
Carboidratos (\%) & $70,51 \pm 0,16^{\mathrm{a}}$ & $66,05 \pm 0,15^{\mathrm{b}}$ & $62,77 \pm 0,06^{\mathrm{c}}$ \\
pH & $5,39 \pm 0,06$ & $4,96 \pm 0,01$ & $4,83 \pm 0,03$ \\
Acidez (\%) & $0,46 \pm 0,00^{\mathrm{a}}$ & $0,77 \pm 0,00^{\mathrm{b}}$ & $1,10 \pm 0,01^{\mathrm{c}}$ \\
Atividade de àgua & $0,24 \pm 0,00^{\mathrm{a}}$ & $0,32 \pm 0,00^{\mathrm{b}}$ & $0,29 \pm 0,00^{\mathrm{c}}$ \\
$L^{*}$ (luminosidade) & $71,74 \pm 0,39^{\mathrm{a}}$ & $61,45 \pm 0,61^{\mathrm{b}}$ & $58,03 \pm 0,46^{\mathrm{c}}$ \\
$a^{*}$ (verde à vermelho) & $6,95 \pm 0,01^{\mathrm{b}}$ & $6,81 \pm 0,07 \mathrm{~b}$ \\
$b^{*}$ (amarelo à azul) & $4,95 \pm 0,39^{\mathrm{a}}$ & $18,08 \pm 0,32^{\mathrm{b}}$ & $15,87 \pm 0,39 \mathrm{c}$ \\
$C^{*}$ ab (intensidade) & $21,86 \pm 1,03^{\mathrm{a}}$ & $19,37 \pm 0,30^{\mathrm{b}}$ & $17,27 \pm 0,38^{\mathrm{c}}$ \\
$\mathrm{h}_{\mathrm{ab}}$ (tonalidade) & $22,41 \pm 1,09^{\mathrm{a}}$ & $1,20 \pm 0,00^{\mathrm{b}}$ & $1,16 \pm 0,00^{\mathrm{c}}$ \\
\hline
\end{tabular}

*Médias com letras iguais na horizontal não diferem entre si pelo teste de Tukey (5\%)

Fonte: Autores (2019)

Em relação à análise da composição centesimal dos biscoitos é interessante observar que os teores de umidade e carboidratos diminuíram conforme o aumento da porcentagem de FBM adicionada, já os teores cinzas, proteínas e lipídeos aumentaram com o aumento da porcentagem de FBM nas formulações, sendo todos estes componentes avaliados na composição centesimal diferentes significativamente entre si ( $p$-valor $<0,001)$. Rigo et al.[23] e Bieli et al.[28] e em seus estudos com snacks acrescidos de FBM observaram o mesmo comportamento detectado neste estudo, concluindo que com o aumento do percentual de adição de FBM ocasionou diminuição dos teores de umidade e carboidratos, e aumento nos teores de cinzas, proteínas e lipídeos.

Analisando as tabelas nutricionais teóricas desenvolvidas com os valores expostos na Tabela 3, conclui-se que ocorre um aumento no teor de fibras do produto conforme o aumento do percentual de adição da FBM em substituição à farinha de trigo. $\mathrm{O}$ teor de fibras aumentou 1,8 vezes da formulação padrão para a formulação com $50 \%$ de $\mathrm{FBM}$ adicionada em substituição à farinha de trigo (quantidade suficiente para 100\%). Ktenioudaki et al.[29], ao analisarem baguetes com adição de bagaço de malte, observou que com 15\% de adição de bagaço de malte em substituição à farinha de trigo o teor de fibras dobrou em relação à formulação padrão (sem adição de bagaço de malte). Também se observa uma pequena elevação no teor de gorduras totais do produto. Os demais componentes não se alteram em quantidade suficiente, a fim de elevar os valores descritos na tabela nutricional final. 
Tabela 3. Tabelas nutricionais teóricas. $\left(^{*}\right) \%$ valores diários de referência com base em uma dieta de 2.000 kcal ou 8.400 KJ. Seus valores diários podem ser maiores ou menores dependendo de suas necessidades energéticas. $\left.{ }^{* *}\right)$ VD não estabelecido. $\mathrm{FP}=$ formulação padrão. F25= formulação com $25 \%$ de farinha de bagaço de malte. F50= formulação com $50 \%$ de farinha de bagaço de malte.

\begin{tabular}{lcccccc}
\hline \multirow{2}{*}{ AMOSTRAS } & \multicolumn{2}{c}{ FP } & \multicolumn{2}{c}{ F25 } & \multicolumn{2}{c}{ F50 } \\
\cline { 2 - 7 } & $\begin{array}{c}\text { Quantidade por } \\
\text { porção }\end{array}$ & VD* & $\begin{array}{c}\text { Quantidade por } \\
\text { porção }\end{array}$ & VD* & $\begin{array}{c}\text { Quantidade por } \\
\text { porção }\end{array}$ & VD* \\
\hline Valor energético & 99 kcal 414 kJ & $5 \%$ & 99 kcal $413 \mathrm{~kJ}$ & $5 \%$ & 99 kcal $413 \mathrm{~kJ}$ & $5 \%$ \\
Carboidratos & $14 \mathrm{~g}$ & $5 \%$ & $14 \mathrm{~g}$ & $5 \%$ & $14 \mathrm{~g}$ & $5 \%$ \\
Proteínas & $1,9 \mathrm{~g}$ & $2 \%$ & $1,9 \mathrm{~g}$ & $2 \%$ & $1,9 \mathrm{~g}$ & $2 \%$ \\
Gorduras Totais & $3,8 \mathrm{~g}$ & $7 \%$ & $3,9 \mathrm{~g}$ & $7 \%$ & $3,9 \mathrm{~g}$ & $7 \%$ \\
Gorduras saturadas & $1,8 \mathrm{~g}$ & $8 \%$ & $1,8 \mathrm{~g}$ & $8 \%$ & $2,0 \mathrm{~g}$ & $9 \%$ \\
Gorduras Trans & $0 \mathrm{~g}$ & $* *$ & $0 \mathrm{~g}$ & $* *$ & $0 \mathrm{~g}$ & $* *$ \\
Fibra Alimentar & $0,5 \mathrm{~g}$ & $2 \%$ & $0,7 \mathrm{~g}$ & $3 \%$ & $0,9 \mathrm{~g}$ & $4 \%$ \\
Sódio & $71 \mathrm{mg}$ & $3 \%$ & $72 \mathrm{mg}$ & $3 \%$ & $72 \mathrm{mg}$ & $3 \%$ \\
\hline Fonte: Autores (2019) & & & & & & \\
\hline
\end{tabular}

Os valores de $\mathrm{pH}$ diminuíram e a acidez aumentou significativamente com o aumento do percentual de FBM adicionado nas formulações de biscoito (Tabela 2). Isto acontece pelo fato do $\mathrm{pH}$ da FBM (Tabela 1) ser mais ácido que o da farinha de trigo. As três formulações apresentaram atividade de água abaixo de 0,60, estando de acordo com o esperado para produtos do tipo biscoitos, sendo estes considerados microbiologicamente estáveis, assim como a FBM produzida ${ }^{[25]}$. Os resultados obtidos para as três formulações são significativamente diferentes entre si ( $p$-valor $<0,001)$.

Os resultados da análise colorimétrica para as três formulações podem ser observados na Tabela 2. O aumento da adição de FBM diminui a luminosidade dos biscoitos F25 e F50, respectivamente. Em relação aos parâmetros $a^{*}$ e $b^{*}$, as amostras F25 e F50 apresentaram coloração marrom, com menores valores de $b^{*}$, enquanto a FP apresentou coloração amarela, com maior valor de $b^{*}$. A partir destes parâmetros pode-se determinar o croma $\left(C_{\mathrm{ab}}{ }^{*}\right)$ e o ângulo hue $\left(\mathrm{h}_{\mathrm{ab}}\right)$, que indicam a intensidade e tonalidade, respectivamente. Com base nos dados apresentados, pode-se concluir que com o aumento da adição de FBM às formulações, a coloração final do produto tornava-se mais escura e intensa, ou seja, com o aumento do percentual de adição da FBM os biscoitos foram adquirindo coloração amarronzada, fazendo com que os valores de $a^{*}$ e $b^{*}$ ficassem cada vez mais próximos dos valores apresentados na Tabela 1 para FBM.

\section{Análise sensorial dos biscoitos}

A Figura 3 registra os resultados obtidos por meio da análise sensorial para a avaliação dos parâmetros sensoriais afetivos de cor, aroma, sabor e textura. Os gráficos A1, B1, C1 e D1 na figura 3 apresentam no eixo $\mathrm{Y}$ a escala de avaliação de 9 pontos, que vai de desgostei muitíssimo até gostei muitíssimo, estando este relacionado ao percentual de respostas dos avaliadores, no eixo $\mathrm{X}$, para cada escala avaliativa. Os gráficos A2, B2, C2 e D2 na Figura 3 apresentam a média da escala avaliativa atribuída para cada amostra. 
Figura 3. Gráficos de análise sensorial de parâmetros afetivos.

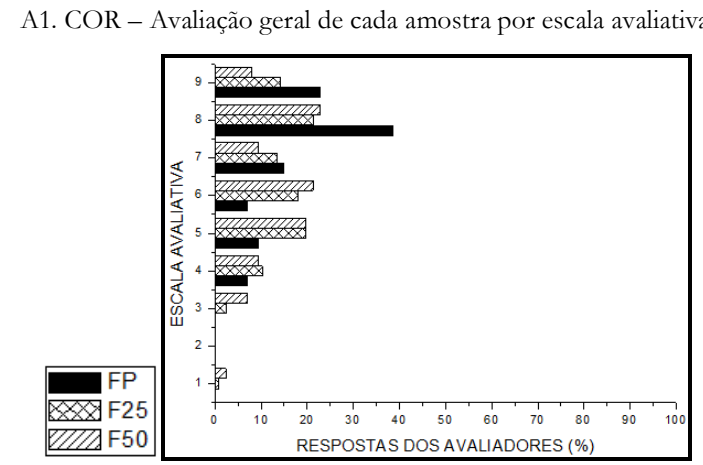

B1. AROMA - Avaliação geral de cada amostra por escala avaliativa

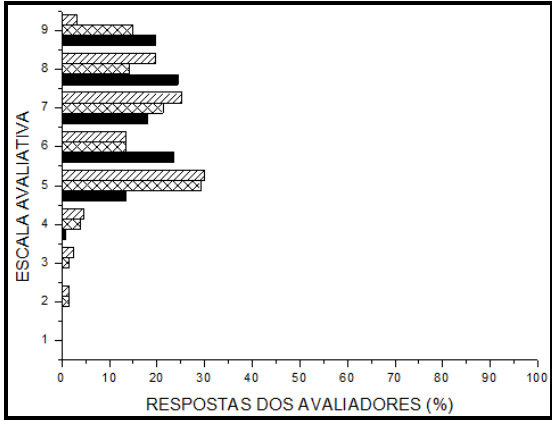

C1. SABOR - Avaliação geral de cada amostra por escala avaliativa

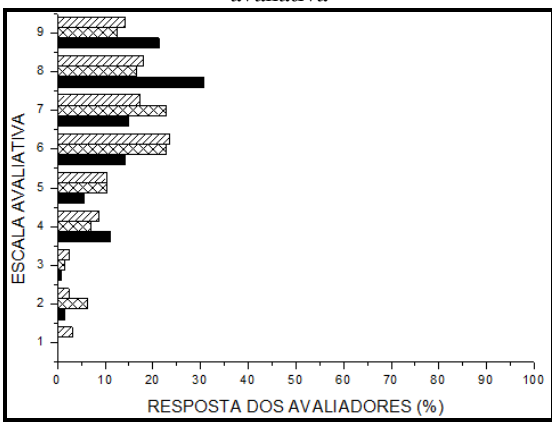

D1. TEXTURA - Avaliação geral de cada amostra por escala avaliativa

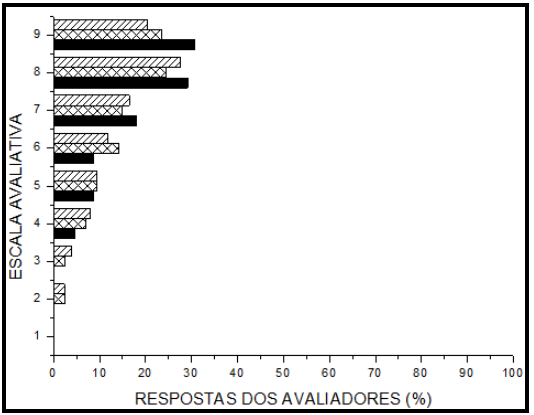

A2. COR - Média das avaliações por amostra

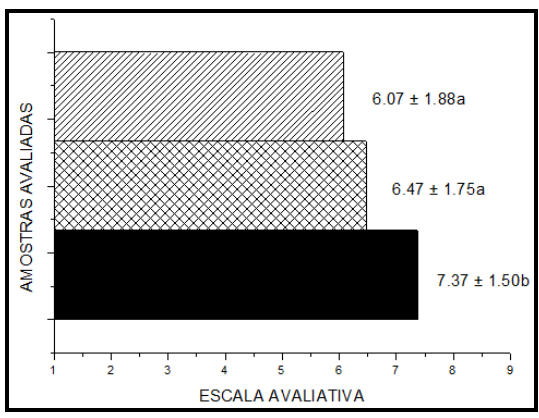

B2. AROMA - Média das avaliações por amostra

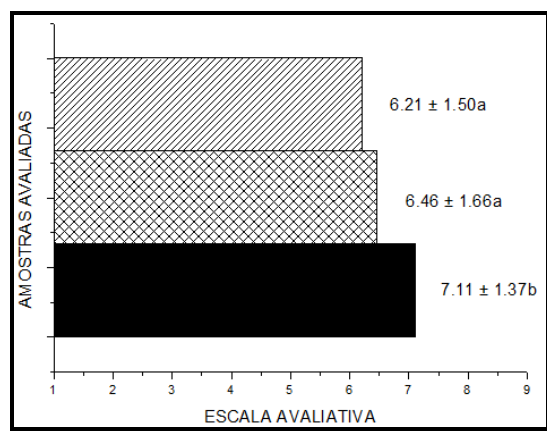

C2. SABOR - Média das avaliações por amostra

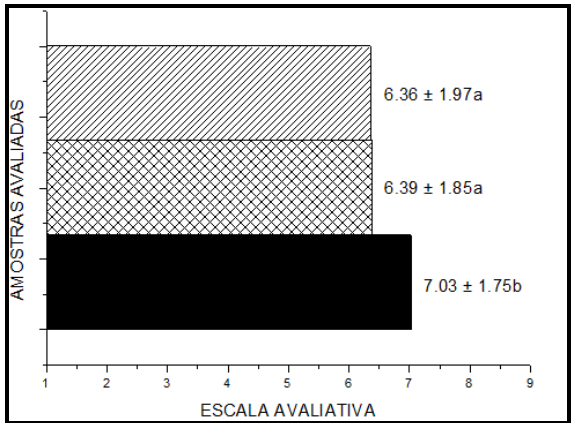

D2. TEXTURA - Média das avaliações por amostra

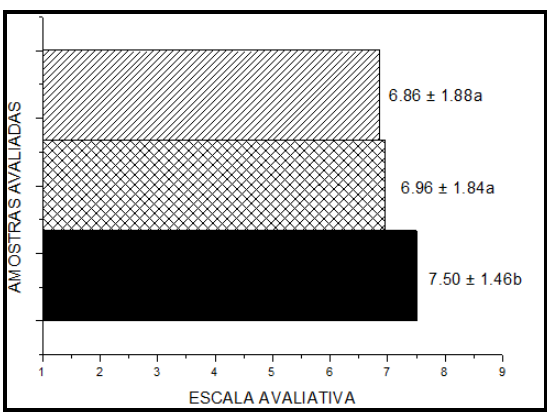

Fonte: Autores(2019) 
Observa-se uma maior preferência dentro da escala avaliativa, por parte dos avaliadores, para a amostra FP, em todos os parâmetros afetivos avaliados. Estatisticamente as avaliações para as amostras F25 e F50 não são significativamente diferentes entre si ( $\not$-valor $>0,05)$, porém as duas são significativamente diferentes da amostra FP. Para todos os parâmetros as avaliações médias permaneceram entre os valores de 6 (gostei ligeiramente) e 8 (gostei muito). Com base nestes dados foram gerados os índices de aceitabilidade para cada atributo dentro de cada amostra, e isto pode ser visualizado na Tabela 4.

Tabela 4. Índice de aceitabilidade das amostras na análise sensorial. FP= formulação padrão. $\mathrm{F} 25=$ formulação com $25 \%$ de farinha de bagaço de malte. F50= formulação com $50 \%$ de farinha de bagaço de malte

\begin{tabular}{lccc}
\hline \multicolumn{1}{c}{ Amostras } & FP & F25 & F50 \\
\hline Cor $(\%)$ & 81,89 & 71,89 & 67,44 \\
Sabor $(\%)$ & 78,11 & 71,00 & 70,67 \\
Aroma $(\%)$ & 79,00 & 71,78 & 69,00 \\
Textura $(\%)$ & 83,33 & 77,33 & 76,56 \\
\hline
\end{tabular}

Fonte: Autores (2019)

Tendo como base o critério de decisão do índice de aceitabilidade igual ou superior a $70 \%$, podese dizer que a amostra F25 apresentou aceitabilidade maior quando comparada à amostra F50, e que a amostra FP foi a que apresentou maior índice de aceitabilidade nesta análise sensorial. A amostra F50 apresentou para cor, sabor e aroma, valores abaixo ou muito próximos de $70 \%$, e apenas para o atributo textura apresentou um valor superior, chegando à $76 \%$. Já a amostra F25 apresentou para todos os atributos valores maiores que $70 \%$.

Panzarini et al. [30], ao analisarem sensorialmente, com 40 provadores, bolo de mel acrescido de bagaço de malte em percentuais de $7 \mathrm{e}$ $10 \%$ em substituição à farinha de trigo, obtiveram maiores índices de aceitabilidade do produto, sendo estes nenhum menor que $80 \%$. Já Mattos[31] analisou sensorialmente pão acrescido de $30 \%$ de bagaço de malte, também com 40 provadores, ao final obteve aceitação do produto superior a $80 \%$. Entretanto nenhum dos dois autores realizou análise sensorial comparativa com uma amostra de formulação padrão, igual a realizada no presente estudo, e isso pode vir a explicar as diferenças de aceitabilidade expostas. Quanto à preferência dos avaliadores pelas amostras ofertadas, demonstrada através do gráfico na Figura 4, que apresenta no eixo $\mathrm{x}$ as escalas avaliativas utilizadas e no eixo y o percentual de resposta dos avaliadores para cada amostra dentro de cada escala avaliativa, observa-se a tendência, já analisada nos parâmetros afetivos, da preferência dos avaliadores pela amostra FP. Desta maneira, a amostra com maior índice de preferência foi a FP, seguida da amostra a F25 e depois a amostra F50, sendo estas significativamente diferentes entre si ( $p$-valor $<0,001)$.

Figura 4. Gráfico da análise de preferência

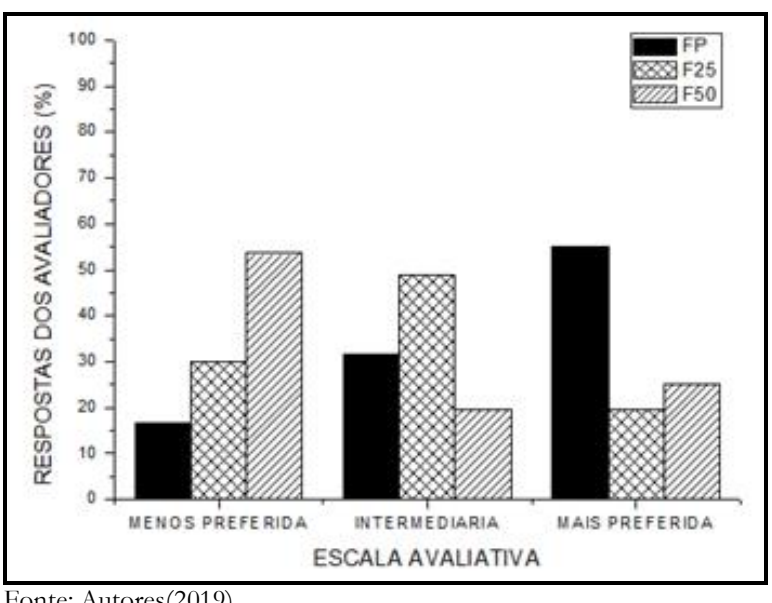

Fonte: Autores(2019)

Quanto à intenção de compra demonstrada através do gráfico na Figura 5, que apresenta no eixo $\mathrm{x}$ 
as escalas avaliativas utilizadas e no eixo y o percentual de resposta dos avaliadores para cada amostra dentro de cada escala avaliativa, todas as amostras obtiveram valores altos para a intenção de compra "SIM", porém a amostra FP foi a que apresentou a maior taxa de intenção "SIM", já para a intenção "NÃO" a amostra F50 foi a que apresentou a maior taxa. Os valores para a intenção "INDIFERENTE" foram similares para as três amostras.

Figura 5. Gráfico da análise de intenção de compra

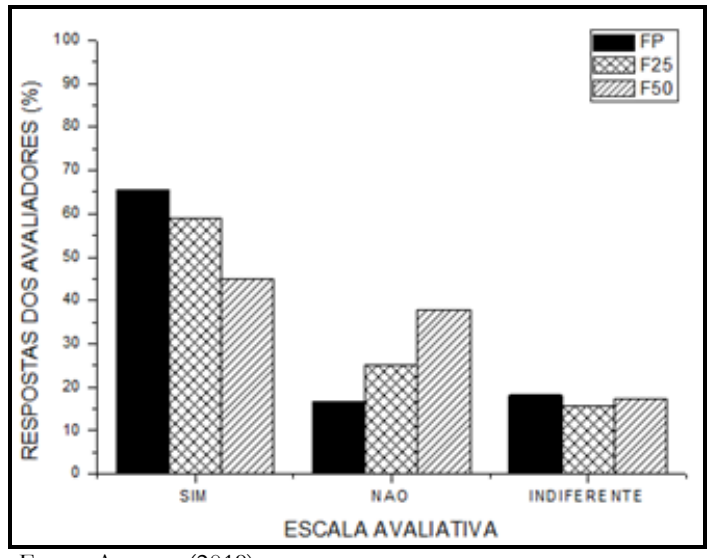

Fonte: Autores (2019)

\section{CONCLUSÃO}

A partir de um processo tecnológico de fácil adaptação foi possível elaborar farinha do bagaço de malte com composição centesimal e propriedades tecnológicas interessantes para a indústria de biscoitos. Nos biscoitos elaborados observou-se aumento no teor de cinzas, proteínas, lipídeos e fibras e diminuição no teor de umidade e carboidratos, conforme o aumento do percentual de farinha de bagaço de malte adicionado em substituição parcial à farinha de trigo. A adição da farinha de bagaço de malte interferiu nos atributos sensoriais. A formulação com $25 \%$ de farinha de bagaço de malte apresentou maior aceitabilidade quando comparada com a formulação com 50\%, com índice de aceitabilidade superior à $70 \%$. Desta forma, entre as condições testadas, recomenda-se a produção de biscoitos com $25 \%$ de farinha de bagaço de malte.

\section{AGRADECIMENTOS}

À estrutura da Universidade Federal de Ciências da Saúde de Porto Alegre (UFCSPA) e à empresa Hunsrück, pelo fornecimento do bagaço de malte.

\section{REFERÊNCIAS}

[1] Cervbrasil - Associação Brasileira da Indústria da Cerveja. Anuário 2016 [Internet]. 2016 [acesso em 2019 mar 14]. Disponível em: http://www.cervbrasil.org.br/novo_site/anuario.

[2] Brasil. Brasil é o terceiro no ranking de produção mundial de cerveja [Internet]. 2017 [acesso em 2019 mar 14]. Disponível em: http://www.brasil.gov.br/economia-e-emprego/2017/08/brasil-eo-terceiro-no-ranking-de-producao-mundial-de-cerveja.

[3] Ministério da Agricultura, Pecuária e Abastecimento - MAPA. Anuário da cerveja no Brasil 2018: crescimento e inovação [Internet]. 2019 [acesso em 2019 mar 14]. Disponível em: http://www.agricultura.gov.br/assuntos/inspecao/produtosvegetal/pasta-publicacoes-DIPOV.

[4] Cervesia - Tecnologia Cervejeira. A cerveja e sua história [nternet]. 2019 [acesso em 2019 mar 30]. Disponível em: https://www.cervesia.com.br/artigos-tecnicos/cerveja/historia-dacerveja/1-a-cerveja-e-sua-historia.html.

[5] Olajire AA. The brewing industry and environmental challenges. Journal of Cleaner Production. 2012;(256). DOI 10.1016/j.jclepro.2012.03.003.

[6] Mussatto SI. Brewer's spent grain: a valuable feedstock for industrial applications. Society of Chemical Industry. Journal Science Food Agriculture. 2014;94:1264-1275.

[7] Santos MS, Ribeiro FM. Cervejas e Refrigerantes. São Paulo: CETESB - Companhia de Tecnologia de Saneamento Ambiental; 2005.

[8] Bonato SV. Método para gestão de resíduos na cadeia cervejeira do Rio Grande do Sul [tese]. Porto Alegre: Universidade Federal do Rio Grande do Sul - UFRGS; 2016.

[9] Fãrcas A, Tofanã M, Socaci S, Mudura E, Scrob S, Salantã L, Muresan V. Brewers' spent grain - A new potential ingredient for functional foods. Journal of Agroalimentary Processes and Technologies. 2014;20(2):137-141.

[10] Almeida AR. Compostos bioativos do bagaço de malte: fenólicos, capacidade antioxidante in vitro e atividade antibacteriana [dissertação]. Curitiba: Universidade Tecnológica Federal do Paraná - UTFPR; 2014. 
[11] Lynch KM, Steffen EJ, Arendt EK. Brewers' spent grain: a review with an emphasis on food and health. Institute of Brewing \& Distilling. 2016; 122:553-568. DOI 10.1002/jib.363.

[12] Associação Brasileira das Indústrias de Biscoitos, Massas Alimentícias, Pães e Bolos Industrializados - ABIMAPI. Anuário 2019. 3. ed. São Paulo: ABIMAPI; 2019.

[13] Mussatto SI, Dragone G, Roberto IC. Brewers' spent grain: generation, characteristics and potential applications. Journal of Cereal Science. 2006;43:1-14.

[14] Batista EA. Estudo do processo de secagem do resíduo de malte gerado na produção de cerveja [trabalho de conclusão de curso]. Paranavaí: Universidade Estadual do Paraná; 2016.

[15] Instituto Adolfo Lutz. Métodos físico-químicos para análise de alimentos. 4. Ed. São Paulo: Instituto Adolfo Lutz; 2008.

[16] Association of Official Analytical Chemists. Official Methods of Analysis. 16. ed. Washington: AOAC; 1997.

[17] Guillon F, Champ M. Structural and physical properties of dietary fibers, and consequences of processing on human physiology. Food Research International. 2000;33:233-245.

[18] Mamede MEO, Suzarth M, Jesus MACL, Cruz JFM, Oliveira LC. Avaliação Sensorial e Colorimétrica de Néctar de Uva. Brazilian Journal Food and Nutrition. 2013;24(1):65-72.

[19] United States Department of Agriculture USDA. Food Composition Databases [Internet]. 2019 [acesso em 2019 jul 27]. Disponível em: https://www.usda.gov.

[20] Brasil. Ministério da Saúde. Agência Nacional de Vigilância Sanitária - ANVISA. RDC no 359, de 23 de dezembro de 2003. Regulamento técnico de porções de alimentos embalados para fins de rotulagem nutricional. Diário Oficial da República Federativa do Brasil. 2003 dez. 23.

[21] Meilgaard M, Civille GV, Carr BT. Sensory Evaluation Techniques. Florida: CRC Press, Inc, Boca Raton; 1999.

[22] Brasil. Ministério da Agricultura, Pecuária e Abastecimento MAPA. Instrução normativa no 8, de 02 de junho de 2005. Regulamento técnico de identidade e qualidade da farinha de trigo. Diário Oficial da União. 2005 jun. 03.

[23] Rigo M, Bezerra JRMV, Rodrigues DD, Teixeira ÂM. Avaliação físico-química e sensorial de biscoitos tipo cookie adicionados de farinha de bagaço de malte como fonte de fibra. Ambiência Guarapuava. 2017;13(1):47-57. DOI 10.5935/ambiencia.2017.01.03.

[24] Desrosier NW. Conservación de Alimentos. 11. ed. México: Editora C.E.C.S.A; 1981.
[25] Gava AJ. Tecnologia de alimentos: princípios e aplicações. São Paulo: Nobel; 2008.

[26] Santana GS, Filho JGO, Egea MB. Características tecnológicas de farinhas vegetais comerciais. Revista de Agricultura Neotropical. 2017;4(2):88-95.

[27] Rodríguez-Ambriz SL, Martínez-Hernández G, González JEC, Trujillo JPP. Composition and functional properties of Lupinus campestris protein isolates. Plants Foods for Human Nutrition. 2005;60:99-107.

[28] Bieli BC, Marques DR, Marchi LB, Quelhas JOF, Chinellato MM, Monteiro CCF, Monteiro ARG. Produção de snack extrusado com adição de farinha de bagaço de malte. Revista Tecnológica. 2014;321-326.

[29] Ktenioudaki A, Chaurin V, Reis SF, Gallagher E. Brewer's spent grain as a functional ingredient for breadsticks. International Journal of Food Science and Technology. 2012;47:1765-1771.

[30] Panzarini NH, Rabbers A, Trindade JLF, Matos EASA, Canteri MHG, Bittencourt JVM. Elaboração de bolo de mel enriquecido com fibras do bagaço da indústria cervejeira. Revista Brasileira de Tecnologia Agroindustrial. 2014;08(1):1154-1164.

[31] Mattos C. Desenvolvimento de um pão fonte de fibras a partir do bagaço de malte [trabalho de conclusão de curso]. Porto Alegre: Universidade Federal do Rio Grande do Sul - UFRGS; 2010. 